\title{
Escola sem partido: representações da neutralidade política e ideológica no trabalho docente
}

\author{
School without a party: representations of political and ideological neutrality in \\ teaching work
}

\author{
Karina Mendonça Miranda ${ }^{1}$ \\ Andreia Cristina Freitas Barreto ${ }^{2}$
}

\section{Resumo}

Esse artigo propõe investigar o entendimento de neutralidade política e ideológica, elaborada pela organização Escola Sem Partido, no trabalho docente. Portanto, buscamos reunir dados com o propósito de responder ao seguinte problema de pesquisa: Como a representação de neutralidade política e ideológica, configurada pela organização Escola Sem Partido, afeta o trabalho docente? Desta forma, essa pesquisa de caráter bibliográfico e documental, sob enfoque qualitativo (GIL, 2008), nos permitiu observar documentos de domínio público e estudos no âmbito nacional sobre o tema em questão, também aqueles que materializam o Escola Sem Partido. Apoiamo-nos nos conhecimentos advindos dos seguintes autores: Azevedo e Santos (2019); Algebaile (2017); Freire (1996 e 2019); Frigotto (2017 e 2019); Miguel (2016); Penna (2016 e 2017); Silveira (2019) entre outros, que nos possibilitou entender sobre as pretensões do fenômeno Escola Sem Partido. Conforme os estudos propostos, a organização Escola Sem Partido se pautou no ultraconservadorismo da burguesia de extrema direita organizada na hierarquia do paternalismo. Buscou reprimir a função do professor e suprimir o direito do aluno em se tornar um cidadão crítico, reflexivo e autônomo. Portanto, caracteriza-se na posição de um projeto doutrinador com a premissa de desmanche e criminalização do trabalho docente.

Palavras-chave: Escola sem partido. Neutralidade política e ideológica. Trabalho docente.

\begin{abstract}
This article proposes to investigate the understanding of political and ideological neutrality, developed by the organization School Without Party, in the teaching work. Therefore, we seek to gather data in order to answer the following research problem: How does the representation of political and ideological neutrality, configured by the School Without Party organization, affect teaching work? In this way, this bibliographic

\footnotetext{
1 Graduada em Letras pela Universidade do Estado da Bahia - Campus XVIII, Eunápolis-BA. E-mail: karina.mendonça@gmail.com

${ }^{2}$ Doutoranda em Educação - UFBA, Mestra em Educação em Ciências - UESC, Pedagoga - FAM. Professora do curso de Letras da Universidade do Estado da Bahia - Campus XVIII, Eunápolis-BA. Integrante do GEPEL UFBA e GRUPAC-UESC. E-mail: andreyafreitas@hotmail.com
} 


\section{-Revista de Iniciação à Docência, v.6, n.2, 2021- Publicação: dezembro, 2021 - ISSN 2525-4332}

and documentary research, under a qualitative approach (GIL, 2008), allowed us to observe public domain documents and studies at the national level on the subject in question, also those that materialize the School Without Party. We rely on the knowledge from the following authors: Azevedo, Santos (2019); Algebaile (2017); Freire (1996, 2019); Frigotto (2017, 2019); Miguel (2016) among others, which enabled us to understand about the pretensions of the School Without Party phenomenon. According to the studies proposed, the organization School Without Party was based on the ultra-conservatism of the extreme right bourgeoisie organized in the hierarchy of paternalism. It sought to suppress the teacher's role and suppress the student's right to become a critical, reflective and autonomous citizen. Therefore, it is characterized in the position of a teaching project with the premise of dismantling and criminalizing teaching work.

Key words: School Without Party. Political and ideological. Neutrality. Teaching work.

\section{Considerações iniciais}

Desde a nossa formação histórica, carregamos a marca estigmatizada de uma sociedade escravocrata e colonizadora; de uma classe dominante, fundamentada no autoritarismo político, na violência com os momentos de ditadura e nos golpes institucionais. A proposta Escola Sem Partido (ESP) se inseriu entre os golpes parlamentares e governamentais da sociedade brasileira em duas fases. A primeira fase (2004-2013) se atrelou aos movimentos, manifestações e organizações conservadoras no processo de mobilização popular, ou seja, manipulação da sociedade civil com posicionamentos ultraconservadores através do fundamentalismo religioso; a segunda fase (2014-2020), se encaixou na sociedade política, a fim de institucionalizar, mediante a Projetos de Lei (PL's) com cunho no moralismo fundamentalista religioso, o programa de controle, principalmente sobre o trabalho docente, e se tornou "uma poderosa teia de relações que surpreende pelo cunho conservador, com várias articulações e redes que perpassam por entidades da sociedade civil, instâncias religiosas e partidos políticos" (ESPINOSA; QUEIROZ, 2017, p. 49).

A partir desse viés, acreditamos que os pressupostos do pensamento neoliberal ${ }^{3}$ permeiam a educação nacional e disputam por uma configuração educacional conservadora e subserviente desde a existência da democracia, especialmente no que diz respeito às políticas de formação profissional. Desta forma, o intento ESP, "Uma proposta que é absurda e letal pelo que manifesta e pelo que esconde" (FRIGOTTO, 2017, p. 31), surgiu na tentativa de atacar a liberdade de ensino sob argumentos que nos

\footnotetext{
3 Harvey (2005) no texto sobre Neoliberalismo: histórias e implicações, afirma que o neoliberalismo é um projeto político de restabelecimento das condições da acumulação do capital e de fortalecimento do poder econômico das elites. Disponível em: https://edisciplinas.usp.br/pluginfile.php/364813/mod_resource/content/o/Ponto\%2001\%20-\%2024-092014\%20-\%20HARVEY\%2C\%20David\%20\%20Neoliberalismo\%20hist\%C3\%B3ria\%20e\%20implica\%C3\%A7\%C3\%B5es\%20-\%2opg\%2011\%20a.pdf Acesso:14 fev. 2021.
} 
espaços educacionais supostamente aconteciam a "doutrinação", conforme assinalam Azevedo e Santos (2019). Com isto, verificamos a restrição de temas para garantir a neutralidade política e ideológica e a privação do profissional professor como mediador no processo ensino-aprendizagem. Portanto, buscamos responder ao seguinte problema de pesquisa: Como a representação de neutralidade política e ideológica, configurada pela organização Escola Sem Partido, afeta o trabalho docente?

A hipótese levantada por essa pesquisa foi de que no trabalho docente a autonomia e a liberdade de ensino precisam ser mantidas sob a perspectiva de cumprir o artigo 206 da Constituição Federal de 1988, consoante ao artigo $3^{\circ}$ da Lei 9394 de 1996 Lei de Diretrizes e Bases da Educação Nacional (LBDEN), uma vez que a educação é um direito social (BRASIL, 2017). Observa-se que o Movimento e Programa ESP buscaram reprimir a função do/a professor/a e suprimir o direito do/a aluno/a em se tornar um/a cidadão/ã crítico/a, reflexivo/a e autônomo/a, visto que se dispõe veemente de ataques ao pluralismo de visões e questionamentos, meio fértil para levar os/as estudantes a construir seu próprio posicionamento, resguardados pelos documentos oficiais.

Para isso, o objetivo da pesquisa foi investigar o entendimento sobre a neutralidade política e ideológica, elaborada pela organização ESP, no trabalho docente. Como a escola foi construída para formar sociedades democráticas, apresentamos os embates discursivos sobre o trabalho docente, por meio de exames dos encadeamentos pensados pelo programa ESP em relação à prática docente no contexto da sala de aula para compreender a liberdade de ensino que o movimento ESP denominou como doutrinação, para entender também a transição dos papéis de agente mediador no processo ensino-aprendizagem para o de doutrinador ideológico partidário.

A inquietação de trabalhar esse tema, surgiu através das discussões nas aulas de Estágio Curricular Supervisionado, do curso de Licenciatura em Letras, e mediante a experiência na monitoria dos Cursos de Extensão de Práticas e Formação Docente propostos pela Universidade do Estado da Bahia (UNEB), os quais possibilitaram a aproximação aos docentes universitários e da educação básica. O estabelecimento do movimento ESP como um projeto de lei, formou um enorme desafio aos docentes, visto que, o/a mediador/a foi ameaçado/a de perder a autonomia; censurado/a devido a temáticas e debates necessários em sala de aula para a construção sócio-histórica dos indivíduos. Essa pesquisa torna-se relevante para o conhecimento acadêmico e social, uma vez que a liberdade de questionar, ser questionado/a, de escutar, de fazer da sala de aula um ambiente aprazível para que os/as alunos/as se sintam confortáveis e seguros/as para dialogar foram ações ameaçadas pelo movimento e programa ESP.

Partindo desse pressuposto, esse texto foi elaborado através de uma revisão bibliográfica, sob enfoque qualitativo (GIL, 2008), possibilitou o contato do pesquisador com o que já se produziu e registrou acerca das atualizações do ESP e os PL's e que deles se frutificaram, com intuito de compreender o posicionamento dos intelectuais do 
espaço educacional a respeito de estratégias que controlaram o trabalho docente. Conforme Lakatos e Marconi (2003), a revisão bibliográfica consiste em buscar os trabalhos acerca de temas específicos que já são de domínio público. A partir destes levantamentos, foram selecionados textos postados no site do ESP de 2016 a 2019. Realizaram-se leituras científicas deste material com a finalidade de compreender posicionamentos trazidos por autores, como Penna (2017), o qual faz reflexões relevantes sobre o "fenômeno" que desqualifica o professor; Azevedo e Santos (2019), que contextualizam como se originou o ESP e quais são os impactos dessa organização na docência; Frigotto (2017 e 2019), que apresenta como a educação tem sido atacada por esse movimento respaldado no conservadorismo; e por Freire (1996 e 2019), o qual defende que o conhecimento é a formação de sujeitos com pensamento crítico, reflexivo e autônomo.

\section{Escola Sem Partido: proposta de retrocesso}

Nessa seção, apresentaremos o surgimento do movimento Escola Sem Partido e como essa formação se repercutiu para tornar-se em programa instituído como Projetos de Lei tramitados no Congresso Nacional (Câmara dos Deputados e Senado Federal). Pretendemos demonstrar como a propagação da organização, aliada à Frente Parlamentar, pautada no fundamentalismo religioso transformou-se num projeto político conservador e doutrinador.

\section{Raízes ultraconservadoras no Escola Sem Partido}

Aparentemente criado em 2004, mediante a revolta de Miguel Francisco Urbano Nagib, um pai religioso, devido uma associação entre São Francisco de Assis e Che Guevara realizada pelo professor de sua filha "supostamente pela dedicação e compromisso de ambos no combate às injustiças e pobreza em suas respectivas épocas" (AZEVEDO; SANTOS, 2019, p. 121), o Movimento ESP deu início às suas discussões. O Movimento ESP foi inspirado nas principais iniciativas norte-americanas que utilizavam o suposto apartidarismo para contestar os posicionamentos dos professores em sala de aula. Apresentadas como No Indocrination 4 criado por Luann Wrigt, alegando visões e atitudes críticas de um professor sobre textos literários "tendenciosos" na escola de seu filho; Campus watch ${ }^{5}$ página online responsável por incentivar discentes a denunciarem professores com condutas contrárias às israelenses; e no Creation Studies Institute (CSI) organização ligada a grupos cristãos dos Estados Unidos, com o objetivo de combater a doutrinação em escolas públicas americanas (ESPINOSA; QUEIROZ, 2017).

Conforme o comentário do senhor Miguel Francisco Urbano Nagib, o Movimento ESP precisou ser criado porque "as pessoas que querem fazer a cabeça das crianças

\footnotetext{
${ }^{4}$ Fundado no site noindocrination.org foi tirado da rede, porém, encontramos depoimentos de casos do Brooklyn College em: http://hnn.us/articles/1236.html. Acesso em: novembro de 2019.

${ }^{5}$ Disponível em: https://www.meforum.org/campus-watch/. Acesso em: novembro de 2019.

${ }^{6}$ Disponível em: http://www.creationstudies.org/. Acesso em: novembro de 2019.
} 
associam as duas coisas e acabam dizendo que Che Guevara é um santo" (EL PAís, 2016), essa fala foi, principalmente, dirigida aos professores. Segundo o senhor Miguel Francisco Urbano Nagib, advogado e procurador do Estado de São Paulo, não teria sido a primeira vez que o professor fez explanações como essas na sala de aula que sua filha estudava. Criador do Movimento ESP, defensor da "neutralidade política e ideológica", julgou os conteúdos como "doutrinação" e que os educandos seriam a "audiência cativa" do professor.

Ele, então, resolveu agir contra o professor e através do relato redigido como carta, Miguel Francisco Urbano Nagib distribuiu as cópias, aproximadamente 300, para os outros pais nas dependências da escola em que a filha estudava. Porém, não obteve o resultado positivo que esperava, afirmou que "Foi um bafafá e a direção me chamou, falou que não era nada daquilo que tinha acontecido. Recebi mensagens de estudantes me xingando. Fizeram passeata em apoio ao professor e nenhum pai me ligou" (EL PAís, 2016).

Esse episódio serviu, para o senhor Miguel Francisco Urbano Nagib, como impulso para criar o movimento. Em entrevista para o jornal El País (2016), o fundador do Movimento ESP pensou na visibilidade que teria através de todos os meios de comunicação ao apresentar, discutir e defender a ideia central do Movimento ESP que se baseou em criticar duas práticas comumente recorrentes nas escolas, segundo ele, a "doutrinação política e ideológica dos alunos por parte dos professores" e a "usurpação dos direitos dos pais na educação moral e religiosa de seus filhos".

Assim, Miguel Francisco Urbano Nagib, se tornou o fundador e líder do Movimento e do Programa Escola sem Partido. Em vários momentos entrou em debate como um dos assuntos frequentemente ligado a educação no Brasil. Além das entrevistas, a movimentação do ESP aconteceu por meio do site oficial7, criado para combater e monitorar as "doutrinações", começou a ter visibilidade em 2014 (MIGUEL, 2016), quando passou a ganhar reconhecimento nacional por ter a "iniciativa contra o uso das escolas e universidades para fins de propaganda ideológica, política e partidária" (ESCOLA SEM PARTIDO, 2019), a existência da doutrinação partidária nas salas de aula das escolas brasileiras foi uma das premissas do Movimento ESP.

\section{Ascensão do Escola Sem Partido com os Projetos de Lei}

As ideias conservadoras do fundador do Movimento ESP encontraram guarida no segmento político fundamentalista religioso (BARBOSA; SOUZA, 2016). A partir do momento que o Movimento ESP entrou em debate, aproveitou-se da onda ultraconservadora, ganhou visibilidade e força no cenário político entre 2014 e 2015, quando o deputado estadual do Rio de Janeiro, Flávio Bolsonaro, demonstrou interesse

\footnotetext{
7 Disponível em: http://www.escolasempartido.org. Acesso em: agosto de 2019.
} 
em criar com Miguel Francisco Urbano Nagib, um projeto fundamentado nas propostas do coordenador da organização.

O Projeto de Lei (PL) 2974/2014 (RIO DE JANEIRO, 2014a), foi o primeiro a ser apresentado em esfera estadual à Assembleia Legislativa do Rio de Janeiro (ALERJ), em 15 de maio de 2014. Em concordância, o irmão do Flávio, vereador Carlos Bolsonaro, apresentou em 3 de junho de 2014 o PL 867/2014 (RIO DE JANEIRO, 2014b) na esfera municipal do Rio de Janeiro, o mesmo projeto com algumas modificações. Portanto, a iniciativa da família Bolsonaro introduziu o Programa ESP como lei (MOURA; PENNA, 2016).

Após o ensejo da formulação do PL, o senhor Miguel Francisco Urbano Nagib disponibilizou-o na página do Movimento ESP. Numa tentativa de desvincular o Programa do Movimento, a seção do site foi transformada em um link que abria uma nova página para o visitante poder baixar os anteprojetos de lei estadual e municipal.

Figura 1: Aviso na página do Movimento ESP para abrir os PL's relacionados ao Programa ESP

Fonte: http://www.escolasempartido.org/, 2016.

A partir dessa iniciativa do site do Movimento ESP, as tramitações de anteprojetos em outros estados começaram, as casas legislativas espalhadas pelo Brasil propunham a instituição do programa também nos municípios.

Tabela 1: Fenômeno por regiões no Brasil depois da disponibilização dos anteprojetos no site

\begin{tabular}{|l|l|}
\hline Região & Número de PL's \\
\hline Norte & 7 \\
\hline Nordeste & 26 \\
\hline Centro-Oeste & 10 \\
\hline Sudeste & 50 \\
\hline Sul & 42 \\
\hline
\end{tabular}

Fonte: Fonte: os autores, 2020.

Fundamentado nesses primeiros projetos, o deputado federal Izalci Lucas do Partido da Social Democracia Brasileira (PSDB/DF) propôs inserir o PL 867/2015, na LDBEN. Esse PL, apensado aos projetos 7180/2014 e 7181/2014 do deputado Erivelton Santana do Partido Social Cristão (PSC/BA), recebeu um parecer positivo na Câmara dos Deputados em 23 de março de 2015. E continuou com fortes impactos na política, 
inclusive nas eleições municipais de 2016, visto que a instrumentalização de denúncias e controle do trabalho docente, segundo Silveira (2019), obteve guarida das Frentes Parlamentares comprometidas com o conservadorismo que concedeu esse caráter ao Congresso Nacional (Câmara dos Deputados e Senado).

A repercussão se deu através do documento com oito artigos normativos sobre a alegação de contaminação política e ideológica com a justificativa abaixo, que foi preservada em todos os projetos:

É fato notório que professores e autores de livros didáticos vêm-se utilizando de suas aulas e de suas obras para tentar obter a adesão dos estudantes a determinadas correntes políticas e ideológicas; e para fazer com que eles adotem padrões de julgamento e de conduta moral -- especialmente moral sexual -- por vezes incompatíveis com os que lhes são ensinados por seus pais (CÂMARA DOS DEPUTADOS, 2015, p. 04).

Segundo pesquisa realizada em 2019 pelo portal Nova Escola, desde a sua notoriedade, o Programa ESP apresentou:

Figura 2: Número de Projetos de Lei no país de 2014 a 2019
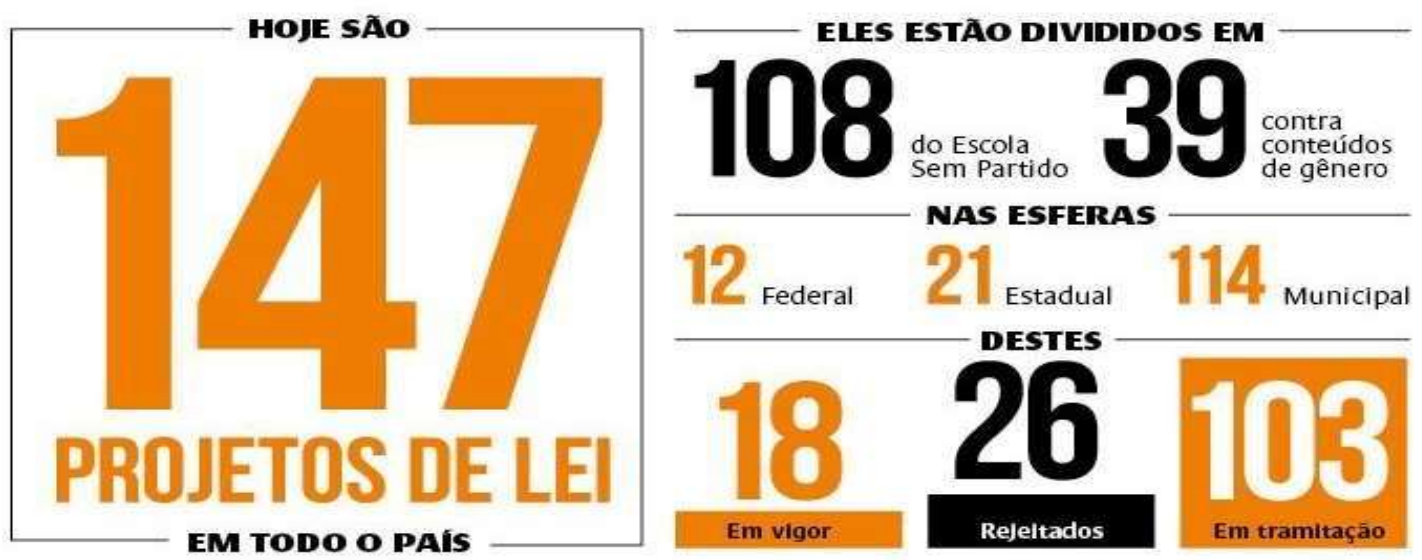

Fonte: https://novaescola.org.br/, 2019.

Com a criação e disponibilização dos anteprojetos como documento no site do programa, Miguel Francisco Urbano Nagib tentou nas bancadas, com cunho fundamentalista e moralista presentes no Congresso Nacional, a alteração da LDBEN, com o intuito de inserir o dever da docência de alcançar a neutralidade política e ideológica, com a pretensão de impedir a alienação dos estudantes. Para Freire (1996), esse processo é como exercitar os discentes para práticas apolíticas, como se fosse possível, enquanto humanos, estar no mundo e ser neutro (FREIRE, 1996). A base do Programa ESP, está relacionada à vertente reacionária, conservadora e fundamentalista que abordou as questões de gênero e diversidade sexual nas escolas como "ideologia de gênero", alegando ser um complô na América Latina, devido ao movimento Com Mis Hijos No Te Metas ${ }^{8}$. Em concordância, Frigotto (2019), pontua que a neutralidade política e ideológica se fundamenta no campo religioso a fim de ressaltar os valores da família que

\footnotetext{
${ }^{8}$ Disponível em: https://www.bbc.com/portuguese/geral-44787632. Acesso em: agosto de 2019.
} 
julga o trabalho docente como doutrinação ideológica (FRIGOTTO, 2019).

\section{Dominação disfarçada de apartidarismo}

No site, na página Quem somos, o advogado apresentou o Movimento ESP como "uma iniciativa conjunta de estudantes e pais", porém, só encontramos os nomes de Miguel Francisco Urbano Nagib, fundador e coordenador da organização (MIGUEL, 2016; ALGEBAILE, 2017) e Bráulio Matos como vice-líder (SILVEIRA, 2019). Primeira ambiguidade do ESP.

Apesar de ter sido criada uma relação discursiva para combater sobretudo a “doutrinação marxista” encontramos outra ambiguidade ao pesquisar sobre a criação e mantenedores do Movimento ESP, notamos que Miguel Francisco Urbano Nagib possuía vínculos com grupo de interesse ou instituição para divulgar conhecimento de cunho político e ideológico. Estava vinculado ao Instituto Millenium, que atuava como um dos mantenedores do Movimento ESP, o principal think tank ${ }^{9}$ da direita brasileira, criado em 2006 a partir de modelos de fundações estadunidenses privadas (MIGUEL; MOURA, 2016).

Além da Associação Escola Sem Partido, pessoa jurídica do movimento, nos defrontamos com Escola Sem Partido Treinamento e Aperfeiçoamento Eireli - ME, uma segunda pessoa jurídica que funcionou como um centro de atividades para desenvolvimento profissional e gerencial que movimentou, cerca de oitenta mil reais, propriedade do procurador. Destarte, a apresentação do Movimento ESP no site que defendeu publicamente a neutralidade política e ideológica entrou em contradição com esses segmentos empresariais (MOURA, 2016). Se tornou um discurso confuso porque Miguel Francisco Urbano Nagib alegou existir contaminações políticas e ideológicas em sala de aula, sendo que ele investia nos grupos de interesse político-ideológico visando transformar a sociedade.

Desde então, a organização autodenominada ESP começou a ser estudada e discutida para obter dimensão da sua índole, suas características e seus procedimentos (ALGEBAILE, 2017). Essa organização que se apresentou como "movimento" se estruturou numa base retrógrada presente desde o período da ditadura militar (1964) através da doutrinação disfarçada de apartidarismo, a qual privou o direito à democracia e à construção da formação humana. Assim, como afirma Frigotto (2017), "Doutrina que, para manutenção de sua agressividade, desliza para a criminalização daqueles que se opõem e na anulação do Estado de direito e na montagem de um Estado policial" (FRIGOTTO, 2017, p. 25).

\footnotetext{
${ }^{9}$ Instituição ou organização que propõe divulgação de pesquisas e propagação de discussões relacionadas ao viés político e ideológico de forma estratégica para ressaltar seus interesses particulares.
} 
Ao observar as estratégias utilizadas para espalhar ataques às esferas políticas democráticas evidenciamos o sentido autoritário e ideológico enraizado na organização que

expressa o epílogo de um processo que quer estatuir uma lei que define o que é ciência e conhecimentos válidos, e que os professores só podem seguir a cartilha das conclusões e interpretações da ciência oficial, uma ciência supostamente não neutra. Para isso, manipula até mesmo o sentido liberal de política, induzindo a ideia de que a escola no Brasil estaria comandada por um partido político e seus profissionais e os alunos seres idiotas manipulados. (FRIGOTTO, 2017, p. 29)

Em conformidade com a ideologia da neutralidade política e ideológica, o Movimento ESP objetivou controlar as atividades escolares e reduzir a atuação da escola e universidades públicas, proposta de desmanche do trabalho docente, "esconde-se a privatização do pensamento e a tese de que é apenas válida a interpretação dada pela ciência da classe detentora do capital” (FRIGOTTO, 2017, p. 29). Ainda segundo o autor,

A construção ideológica da noção de capital humano, ao mesmo tempo em que induz a uma visão invertida da desigualdade, estabelece uma mudança profunda e regressiva na concepção republicana de educação básica, pública, gratuita, universal e laica. A educação escolar deixa de ser concebida como um direito social e subjetivo universal e, se é definida como investimento em capital (capital humano), passa a reger-se pelos critérios e leis mercantis (FRIGOTTO, 2017, p. 27).

A ampliação da crise econômica mundial transformou os direitos conquistados num grande problema para a classe dominante brasileira que não renunciou seus privilégios e resolveu atacar o poder público, com intenção de nutrir a desigualdade e exclusão (fatores assimétricos no Brasil) através da pedagogia do medo e da violência. Um processo regressivo e agressivo que os opositores são criminalmente anulados. Caminhamos para a destituição de um Estado democrático e instituição de um Estado ditador orquestrado pela manipulação da opinião pública por meio da mídia, em tempo real (FRIGOTTO, 2017).

\section{Censura na docência: mediação ameaçada pelo Escola Sem Partido}

Já nessa seção, abordaremos sobre como o movimento e programa Escola Sem Partido se difundiu na docência, com base na premissa de neutralidade política e ideológica. Dado que a proposta da organização foi de retirada de pautas necessárias para a formação histórica e cultural dos indivíduos, além do apagamento da identidade docente.

\section{Neutralidade e doutrinação: devaneios de controle do trabalho docente}

Como vimos, o Movimento ESP se disseminou por meio de uma linguagem simples nas redes socias. Se expandindo em um cenário de crise política, a partir do Pós-Golpe de 2016, onde vários projetos tramitaram no Congresso Nacional e, com aprovação, como o 
caso da BNCC (BRASIL, 2017). Nesse contexto de desmontes, o trabalho docente foi afetado devido aos princípios ditadores do Programa ESP que colocaram em xeque a integralidade, cidadania e autonomia do agente mediador no processo ensinoaprendizagem. (ZAN; MAZA, 2018).

Na primeira página do site oficial "Escola Sem Partido" encontramos as abas Home, Quem somos, Programa Escola Sem Partido, Blog, Perguntas e Respostas; logo abaixo tem notícias sobre as supostas doutrinações, links, artigos e depoimentos. Tratase de um instrumento de denúncias, de acordo com a fala de Miguel Francisco Urbano Nagib, se inspirou no Código de Defesa ao Consumidor"10 "que intervém na relação entre fornecedor e consumidor, coerentemente com a sua visão contratualista e paternalista de sociedade" (SILVEIRA, 2019, p. 33). Vale destacar que o trabalho docente não está expresso nesse documento, mas usaram como referência para criar as regras com o intuito de controlar e criminalizar o trabalho dos/as professores/as. Com bases profundas fundamentadas no capitalismo, fundamentalismo religioso, politização conservadora, anticomunismo, crescimento do pensamento neoliberal, reprovação do marxismo nos debates acadêmicos e reducionismo do pensamento crítico com a imposição da neutralidade (MIGUEL, 2016).

A justificativa para regulamentar essa ideia foi de que os/as alunos/as tinham sofrido assédio pelos grupos de professores/as que acreditam em correntes políticas e ideológicas progressistas, comparou as escolas a "caixas de ressonância" devido a doutrinação, encontra-se na apresentação do site do Movimento ESP:

\begin{abstract}
A imensa maioria dos educadores e das autoridades, quando não promove ou apoia a doutrinação, ignora culposamente o problema ou se recusa a admiti-lo, por cumplicidade, conveniência ou covardia. A pretexto de transmitir aos alunos uma "visão crítica" da realidade, um exército organizado de militantes travestidos de professores prevalece-se da liberdade de cátedra e da cortina de segredo das salas de aula para impingir-lhes a sua própria visão de mundo. (ESCOLA SEM PARTIDO, 2019, p. 02).
\end{abstract}

O inciso I do artigo $2^{\circ}$ do PL 867/2015 foi embasado nesse pensamento, criado para determinar normas para a educação nacional. Nesse artigo consta o princípio de "neutralidade política, ideológica e religiosa do estado" (CÂMARA DOS DEPUTADOS, 2015, p. 01). Relacionado a esse princípio de neutralidade, está o $4^{\circ}$ artigo que dispõe deveres ao/a docente, no inciso I, elencado como norteador do PL 246/19: "não se aproveitará da audiência cativa dos alunos para promover os seus próprios interesses, opiniões, concepções ou preferências ideológicas, religiosas, morais, políticas e

\footnotetext{
${ }^{10}$ Em audiência pública no Senado Federal no dia 01 de setembro de 2016, Miguel Francisco Urbano Nagib afirmou que: "O nosso projeto foi inspirado no código de defesa do consumidor. O Código de defesa do Consumidor intervém na relação entre fornecedores e consumidores para proteger a parte mais fraca, que é o consumidor, o tomador dos serviços que são prestados pelos fornecedores. Da mesma forma, a nossa proposta ela intervém na relação de ensino-aprendizagem para proteger a parte mais fraca dessa relação que é o estudante, aquele indivíduo vulnerável, que está se desenvolvendo" (Miguel Nagib, 2016). Disponível em: https://www.youtube.com/watch?v=jwGErV-1zUo. Acesso: 19 out. 2021.
} 
partidárias" (CÂMARA DOS DEPUTADOS, 2019, p. 01). No site, o ESP acusa docentes de infringirem esse princípio constitucional:

O professor que se aproveita de suas funções e da presença obrigatória dos alunos em sala de aula para promover suas próprias concepções e preferências ideológicas, políticas e partidárias viola o princípio constitucional da neutralidade política, ideológica e religiosa do Estado (ESCOLA SEM PARTIDO, 2019, p. 02).

A definição de neutralidade é um paradoxo. Segundo Gondim (2014), pode ser definida como um conjunto de teorias políticas presentes nos partidos políticos desde a Modernidade, com a noção de descrever e estruturar sua própria neutralidade, e com a finalidade de estabelecer regras de aproximação ou distanciamento entre a ética e a política. Porém, percebemos aqui uma imagem juridicamente construída para conceituar esse termo. Sabemos que o Movimento ESP por ter sido criado por um advogado, utilizou-se de termos jurídicos para criar mecanismos de legitimação do seu projeto. E de acordo com Bittencourt (2017), essa premissa de neutralidade evidencia a subserviência da práxis educacional aos preceitos neoliberais da "privatização da vida e da mercantilização da cultura em nome da concretização inapelável do sistema capitalista e seu inerente processo de formatação unidimensional da existência" (BITTENCOURT, 2017, p. 119).

Além disso, as pretensas do Programa ESP também mencionam a luta pela “descontaminação e desmonopolização política e ideológica das escolas" (ESCOLA SEM PARTIDO, 2019). Se utilizam do inciso IV do artigo 12 da Convenção Americana sobre os Direitos Humanos (Pacto de San José da Costa Rica ${ }^{11}$ ), com o intuito de defender o poder total dos pais ou tutores em aplicar a educação moral sobre seus filhos ou pupilos de acordo com suas convicções, como fundamento para exigir a liberdade de consciência e de religião. No entanto, a Convenção trata da proteção do espaço privado de interferências do poder público, enquanto o Programa ESP interpretou ao contrário, impetrou as vontades privadas sobre o espaço público (PENNA, 2017).

O devaneio de controle do trabalho docente se deu quando o Movimento ESP apresentou a segregação de formação e conteúdo, sendo a formação incumbência da família e o conteúdo função do/a professor/a (CARVALHO, 2019). Também impôs o distanciamento da disciplina com o mundo real, "o professor não poderia discutir essa realidade, ele teria que se ater à sua matéria - e nós sabemos que isso na prática é impossível, porque dialogar com a realidade do aluno é um princípio educacional estabelecido para tornar o ensino das disciplinas significativo" (PENNA, 2017, p. 37).

\footnotetext{
11 A Convenção Americana sobre Direitos Humanos foi assinada na Conferência Especializada Interamericana sobre Direitos Humanos, em San José, Costa Rica, em 22 de novembro de 1969. A mesma está disponível na íntegra no site: https://www.cidh.oas.org/basicos/portugues/c.convencao_americana.htm. Acesso em: jun. 2020.
} 


\section{Língua Portuguesa sem partido, como pode?}

Essa seção toma como base a disciplina de Língua Portuguesa por ser o campo de atuação das autoras. É válido destacar que, quando trabalhamos gêneros textuais e nos deparamos com o gênero notícia, por exemplo, é inconcebível trabalhar esse tema sem atingir a realidade do/a aluno/a, pois ele/a carrega conhecimentos além dos muros da escola, apresenta seu conhecimento de mundo.

A discussão da organização ESP se refere "à retirada do pensamento crítico, da problematização e da possibilidade de democratizar a escola, esse espaço de partilhas e aprendizados ainda tão fechado, que precisa de abertura e diálogo" (MANHAS, 2016, p. 16). Sabemos que se trata de uma partidarização guiada pelo conservadorismo encontrado na direita e extrema direita que atualmente governam a sociedade brasileira.

Ao observar o Plano Nacional de Educação ${ }^{12}$ (PNE) e a $\mathrm{BNCC}^{13}$ percebemos que as construções foram interrompidas e/ou alteradas pelos debates e moldes do Programa ESP em censurar termos de "promoção das equidades de gênero, raça/etnia, regional e orientação sexual, que acabou excluída do texto do projeto" (MANHAS, 2016, p. 16). Tais características seriam detectáveis nos momentos de aulas explicativas, material didático e nos programas ou atividades de formação vinculadas ao/ professor/a (ALGEBAILE, 2017). Então, críticos/as do Programa ESP (ZAN; MAZZA, 2018; AZEVEDO; SANTOS, 2019; FRIGOTTO, 2019; FERREIRA; FERRAZ, 2020; FERRAZ, 2020) questionaram para quem seria o "comum" da BNCC, uma vez que esse documento é anacrônico e não contempla a todos.

Na organização do ESP percebemos o discurso hegemônico de desvalorização das Ciências Humanas e Sociais instaurado pelo Programa ESP, se constitui em um retrocesso de conquistas educacionais, o qual afeta o trabalho docente, reprime a autonomia, o currículo e as discussões reflexivas. Em detrimento à base positivista com visões que colocam a educação a serviço do capital "daí a sua concepção estritamente materialista (...). O dinheiro é a medida de todas as coisas. E o lucro, seu objetivo principal" (FREIRE, 2019, p. 63). Ou seja, voltamos ao período da década de 1960, passagem da ditadura militar, em que Paulo Freire apontou a educação bancária, sob a alegação da "passividade e ingenuidade" dos/as discentes em receber os "depósitos" de professores/as.

Em lugar de comunicar-se, o educador faz "comunicados" e depósitos que os educandos, meras incidências, recebem pacientemente, memorizam e repetem. Eis aí a concepção "bancária" da educação, em que a única margem de ação que se oferece aos educandos é a de receberem os depósitos, guarda-los e arquiválos. Margem para serem colecionadores ou fichadores das coisas que arquivam. No fundo, porém, os grandes arquivados são os homens, nesta (na melhor das hipóteses) equivocada concepção "bancária” da educação. Arquivados, porque fora da busca, fora da práxis, os homens não podem ser. Educador e educandos

\footnotetext{
12 PNE 2014-2024 foi instituído pela Lei 13.005, de 2014. Disponível em: http://pne.mec.gov.br/18-planossubnacionais-de-educacao/543-plano-nacional-de-educacao-lei-n-13-005-2014. Acesso em: ago. de 2020.

13 BNCC foi homologada pela Portaria do MEC $n^{\circ} 1.348$, de 14 de dezembro de 2018, conforme Resolução CNE/CP n 2/2017 e Parecer CNE/CP n 15/2017.
} 


\section{-Revista de Iniciação à Docência, v.6, n.2, 2021- Publicação: dezembro, 2021 - ISSN 2525-4332}

se arquivam na medida em que, nesta distorcida visão de educação, não há criatividade, não há transformação, não há saber. (FREIRE, 2019, p. 81).

As temáticas e as discussões em torno dos textos advindos da disciplina de Língua Portuguesa que proporcionam a invenção e a reinvenção para a produção de criticidade de como ler o mundo, tornam-se ameaçadas ou até se perdem com o estabelecimento de restrição de conteúdo idealizada pelo Movimento ESP. Dessa maneira, o conhecimento fica silenciado e torna-se líquido, sem solidez. A imposição de um conhecimento e não de outro atinge a capacidade humana de pensar logicamente. Uma censura velada ao exercício da comunicação e da atuação social, tarefa que exige acesso aos posicionamentos plurais para predeterminar e implicar, através da reflexão, qual caminho trilhar fundamentado em bases epistemológicas construídas nas salas de aula.

Por conseguinte, um pensamento crítico, reflexivo e autônomo se desenvolve a partir de leituras, escritas, debates com argumentação, pontos de vista diferentes que contribuem para o contra-argumento $e$ as diversas informações concretas e questionáveis vindas do meio tecnológico em que nos encontramos imersos. "A liberdade amadurece no confronto com outras liberdades, na defesa de seus direitos em face da autoridade dos pais, do professor, do Estado" (FREIRE, 1996, p. 105).

Afinal, a Língua Portuguesa não pode ser neutra, porque não existe neutralidade política, ideológica e religiosa no Estado, se assim fosse, todo o percurso histórico, cultural e social, formadores identitários que compõem as histórias dos/as docentes e discentes não existiria. Portanto, o processo de ensino-aprendizagem, conforme Freire (1996), é o momento de significação e ressignificação, possibilidades de desconstrução e construção do conhecimento, o qual liberta e fomenta o sonho de uma sociedade igualitária.

\section{Investidas do Escola Sem Partido sobre a identidade docente}

O trabalho docente foi alvo da onda reacionária, em vigor desde 2017, juntamente com diversos partidos políticos e grupos religiosos, com contínuos golpes voltados contra a dignidade do/a professor/a (SOUZA; FERREIRA, 2019; BARRETO; ROCHA, 2020; FERREIRA; ABREU, 2021; FERREIRA; FERRAZ, 2021; SANTOS; BARRETO, 2021), que evidenciamos como um ataque de criminalização ao agente mediador que busca por intermédio do conhecimento a construção de espaços de resistência contra o conservadorismo imposto pela dominação. Dentre os ataques, encontramos tentativa de retirada da autonomia docente e o controle de suas atividades através das imposições de neutralidade. São disposições reacionárias ideológicas partidárias que não aceitam o desenvolvimento e a liberdade desses sujeitos nos espaços educacionais (PENNA, 2017).

Para além de seu simplismo devido a autodenominação, a organização ESP encobre questões complexas como o enfraquecimento do trabalho docente e a acusação da suposta doutrinação marxista, já que 


\title{
-Revista de Iniciação à Docência, v.6, n.2, 2021- Publicação: dezembro, 2021 - ISSN 2525-4332
}

visa criminalizar todo tipo de discurso pedagógico imputado como sectário de ideologia política ou religiosa, em favor da preservação da pretensa liberdade de consciência dos estudantes, afetados pelo arbítrio tirânico dos professores que fazem do seu exercício docente um espaço de politização discursiva. (BITTENCOURT, 2017, p. 119).

Doutrinador ideológico partidário e tirano foi como a organização ESP descreveu a identidade do/a docente, e pretendeu com suas concepções de neutralidade política e ideológica mudar para "imparcialidade passional - o professor torna-se mero transmissor de conteúdo para alunos passivos" (SILVEIRA, 2019, p. 26). Observa-se que nessa pretensão há uma enorme contradição, visto que se mostra como uma nova configuração para o docente, todavia, está fundamentado no conservadorismo, que incita os delatores (alunos/as e pais) a realizarem denúncias do que considerar inadequado. Uma verdadeira despolitização e eliminação de pluralidade prevista na LDBEN. Cerceamento da liberdade de ensinar (RAMOS; SANTORO, 2017).

Sabemos que a posição de professor/a não se caracteriza como tirânica e tampouco de doutrinação, mas como uma via de mão dupla em que professor e aluno

\begin{abstract}
precisam ser respeitados e considerados em sua integralidade, inseridos na sociedade sob uma perspectiva cidadã e autônoma, de exercício de plenos direitos - civis, políticos e sociais. Essa perspectiva, por sua vez, responde a um longo processo de evolução que remete a um projeto de educação com respaldo nas leis brasileiras: a Constituição de 1988, o Estatuto da Criança e do Adolescente (ECA), a Lei de Diretrizes e Bases da Educação Nacional (LDBEN), o mais recente Plano Nacional de Educação (PNE) e a Base Nacional Comum Curricular (BNCC). (MARINHO; IERVOLINO; NOCOLAV, 2016).
\end{abstract}

Defendido e constitucionalizado pelas leis brasileiras, o trabalho docente vai muito além da entrega do conteúdo na sala de aula. Com a evolução digital, esses conteúdos programáticos e curriculares deixam de ser o foco, passam para a construção de saberes fundamentais na formação da criticidade, socialização e responsabilidade social em comunidade. Segundo Giroux (1997), o/a professor/a é agente transformador, uma vez que se trata de uma atividade que envolve uma ou diversas formas de pensamento. $E$ define que o trabalho docente não pode e nem deve ser neutro, declara que os/as professores/as devem

assumir responsabilidade ativa pelo levantamento de questões sérias acerca do que ensinam, como devem ensinar e quais são as metas mais amplas pelas quais estão lutando, sendo isso o compromisso pela formação dos propósitos e condições de escolarização (GIROUX, 1997, p. 161).

Por conseguinte, não é possível defender neutralidade nas relações de contexto educacional, dado que essas relações são historicamente fundamentadas nos princípios sociológicos, filosóficos e culturais. Nesse sentido, na tentativa de implantação de uma suposta neutralidade política e ideológica, destacamos que o Programa ESP não possui caráter educacional, dado que

a concepção de docência implícita neste PL está fortemente ligada ao sentido do trabalho do professor, ou melhor, à criminalização do trabalho docente. A concepção aqui é de que os docentes não são mais educadores, mas instrutores técnicos prontos a serem denunciados caso não sigam a cartilha hegemônica de 


\section{-Revista de Iniciação à Docência, v.6, n.2, 2021- Publicação: dezembro, 2021 - ISSN 2525-4332}

\section{uma classe dominante, autoritária e cerceadora de direitos formada pelos} proponentes do abusivo PL. (OLIVEIRA; CERNY; AVILA, 2018, p. 254).

Baliza a identidade docente num nível que limita a profundidade de sua bagagem teórica e cultural, a ponto de desvalorizar a capacidade reflexiva dos/as profissionais. Assim como Frigotto (2017), os princípios que formam o PL de normatização para controle do trabalho docente, constroem uma imagem depreciativa da identidade desse/a professor/a e naturalizam a rotatividade desse lugar tão importante para a formação de uma cidadania democrática, apoiam a retirada do/a profissional de sua função e substitui facilmente por aquele/a que esteja apto/a ou desposto/a seguir os comandos mercadológicos, ainda que não tenha formação para tal função. Inclusive, a proposta de demissão em massa dos professores apontados como doutrinadores ${ }^{14}$, de acordo com o projeto ESP, fez parte da campanha das eleições presidenciais em 2018, do atual presidente do Brasil, Jair Messias Bolsonaro.

Seguindo seu caráter controlador, intimidador e punitivo, o Programa ESP regulamentou um cartaz de Deveres do Professor, com o objetivo de transformar os/as alunos/as que eram suspostamente doutrinados/as em meros fiscais e entregar esse/a professor/a ao site através de depoimentos, também com gravações dessas aulas para comprovar e criminalizar o/a docente.

Figura 3: Cartaz de Deveres do Professor, segundo o Programa ESP

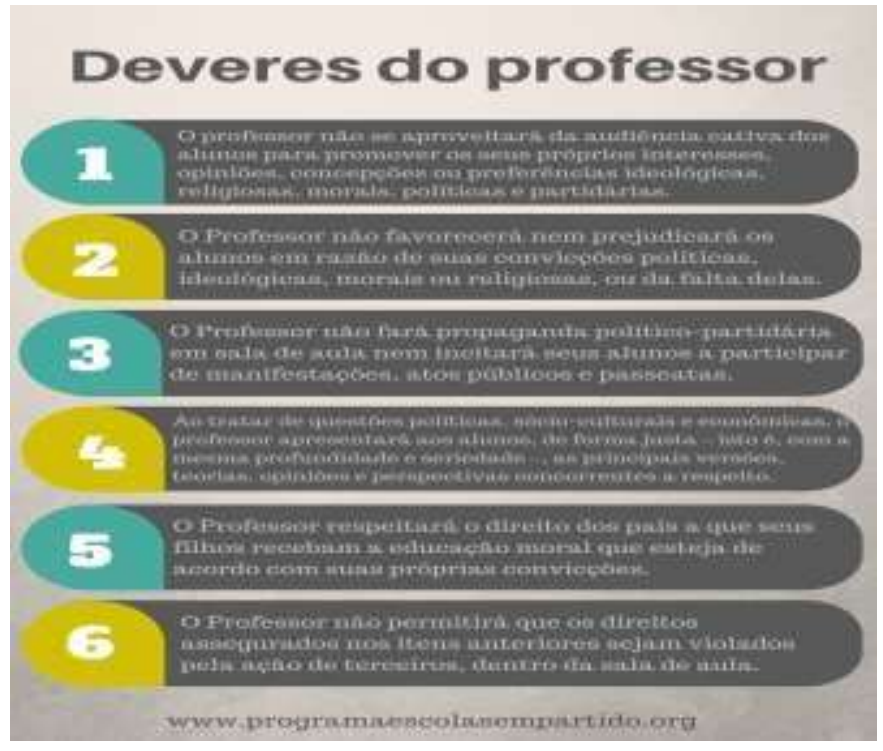

Fonte: http://www.escolasempartido.org/blog/deveres-do-professor/, 2020

O cartaz é composto por seis itens, criados pelo Programa ESP, a partir das interpretações equivocadas do senhor Miguel Francisco Urbano Nagib sobre as legislações basilares da educação brasileira. Nota-se que são regras criadas sem referência teórica ou justificativa plausível. É importante lembrar que, esse cartaz foi criado para "encantar" os pais ou tutores, que ao ler superficialmente podem achar pertinente a ideia de neutralidade política e ideológica exposta nos itens. Essa ideia configura a identidade do/a professor/a de agente mediador para transmissor de

\footnotetext{
${ }^{14}$ Disponível em: https://www.justificando.com/2018/12/12/escola-sem-partido-ja-provoca-demissoes-e-transferências-relatam-professores/. Acesso em: jul. de 2020.
} 
conteúdo. O Programa ESP é resultado das disputas políticas cíclicas que "emerge das contradições da fase imperialista do capitalismo" (TAFFAREL; JÚNIOR; CARVALHO; BELTRÃO, 2019, p. 167).

\section{Considerações finais}

Desenvolvemos nesse artigo um diálogo com teóricos, com documentos oficiais que compõem a legislação educacional brasileira e com os próprios princípios do ESP. Almejamos identificar os elementos trazidos pelo ESP que afetaram diretamente 0 trabalho docente, uma vez que os preceitos buscaram estabelecer a naturalização de uma educação tecnicista. Dessa forma, sob o pressuposto de neutralidade política e ideológica, o ESP feriu a liberdade de cátedra e deslegitimou o trabalho docente, principalmente da escola pública. As observações do material publicado no site e dos dois PL's propostos na câmara dos deputados, indicaram uma visão produtivista com o objetivo de moldar as escolas em grandes empresas, ou seja, pautada na racionalidade econômica.

Percebemos que a organização ESP foi muito além da discussão levantada por um pai religioso, tratou-se de representações da crise histórica cíclica que se disseminou no Brasil desde a década de 1960, quando os primeiros sinais de conservadorismos apareceram. Desde então, esses sinais aumentaram e nos colocaram na posição de temporalidade neoliberal ultraconservadora, momento de propagação dos objetivos políticos da burguesia de extrema direita organizada na hierarquia do paternalismo e nos elementos que compuseram a internacionalização da economia e da tecnologia. Foram conjecturas criadas pelos detentores do capital que através da privatização salientaram desmanchar os setores públicos, a escola pública e todos os direitos trabalhistas, ou grande parte deles, conquistados pela classe trabalhadora. E esses objetivos se difundiram no Programa ESP que se manifestou na segunda década do século XXI.

A sociedade brasileira se tornou um campo de guerras sociais, onde, obrigatoriamente, para conquistar a entrada e permanência nos espaços públicos, precisa-se de um conflito. Assim se formou a democracia que conhecemos e foi ameaçada por uma organização que se intitulou como movimento, a qual através de seus apoiadores tentaram privar a liberdade de ensinar conquistada na Constituição Federal de 1988, documento basilar da educação. Assim, o trabalho do/a professor/a foi criminalizado a partir da suposta doutrinação política e ideológica.

Por meio do levantamento pautado nas concepções de Frigotto (2017 e 2019), Penna (2016 e 2017), Freire (1996 e 2019), Silveira (2019), Miguel (2016), Azevedo e Santos (2019), Espinosa e Queiroz (2017), Zan e Maza (2018) entre outros, observou-se que a noção de participação do indivíduo em sociedade sofreu com a manipulação da classe conservadora, a qual tentou sacrificar a educação emancipadora e libertária através do discurso de ódio aos/as professores/as com o intuito de frear a formação crítica da sociedade brasileira. Interessante lembrar que o comportamento participativo dos indivíduos foi concebido como "doutrinador" pelo Movimento ESP. Desse modo, os cidadãos de escolas públicas não poderiam se expressar e se posicionar criticamente, visto que o cumprimento dos PL's inspirados no Movimento ESP colocaria a população 
desfavorecida dos privilégios em lugar de subalternidade, essa concepção nos fez lembrar do período de escravidão.

Para o Movimento ESP, os/as docentes têm imenso poder sobre os/as discentes, como se o/a aluno/a fosse "submisso/a à autoridade do/a professor/a". Porém, essa afirmação não se sustenta na realidade brasileira porque os/as alunos/as não são sujeitos ignorantes e o fato de serem alunos/as não os/as classificam no nível de desconhecimento da vida. Pelo contrário, são indivíduos que possuem conhecimentos e que são considerados no processo de ensino-aprendizagem, uma via de mão dupla, tanto o/a docente quanto o/a discente aprendem simultânea e instantaneamente. Nesse percurso, os indivíduos tornam-se protagonistas de suas próprias histórias. Exemplos desse protagonismo são as manifestações por direitos iguais, por participação social e ocupações por melhorias de órgãos públicos, são eventos liderados pelos/as próprios/as estudantes.

Portanto, educação não é doutrinação sequer o/a docente doutrinador/a. A constituição que rege a liberdade de ensinar e de aprender, defende que essa troca aconteça numa perspectiva plural e com respeito às diferenças. Sendo assim, o/a educador/a tem um forte papel político-pedagógico, já que não existe educação neutra. A educação pode ajudar a converter os excluídos em sujeitos da sua história e para que essa conversão ocorra, não serve qualquer tipo de educação, mas uma educação libertadora, reflexiva, crítica e dirigida à responsabilidade social e política.

\section{Referências}

ALGEBAILE, Eveline. Escola sem Partido: o que é, como age, para que serve. In: FRIGOTTO, Gaudêncio (Org.). Escola "sem" partido: esfinge que ameaça a educação e a sociedade brasileira. Rio de Janeiro: UERJ, LPP, p. 63-74, 2017.

AZEVEDO, Mauri de Castro; SANTOS, Marcolino Sampaio dos. Escola sem partido e as implicações na liberdade de ensino na docência universitária. In: BARRETO, Andreia Cristina Freitas; SANTOS, Jaciara de Oliveira Sant'Anna. Da formação à prática pedagógica: olhares plurais. Rio de Janeiro (RJ): Bonecker, p. 117-144, 2019.

BARBOSA, Wilmar do Valle; SOUZA, Andréa Silveira de. Iniquidade ou elã neofundamentalista? Considerações sobre religião e política no Brasil. In: Numen: Revista de estudos e pesquisa da religião. Juiz de Fora, v. 19, n. 2, p. 113-140, 2016. Disponível em: https://doi.org/10.34019/2236-6296.2016.v19.22042. Acesso em: jul. 2020.

BARRETO, Andreia Cristina Freitas, ROCHA, D. S. Covid-19 e Educação: Resistências, Desafios e (Im)Possibilidades. Revista Encantar - Educação, Cultura e Sociedade - Bom Jesus da Lapa, v. 2, p. 01-11, jan./dez. 2020. ORCID: https://orcid.org/0000- 0001-9555-5778. Acesso: 14. jul. 2021.

BITTENCOURT, Renato Nunes. A impossível neutralidade discursiva na práxis educacional e aimprobidade ideológica da Escola sem Partido. In: Revista Espaço Acadêmico, Maringá, Paraná, v. 16, n. 191, dez. 2017. Disponível em: http://periodicos.uem.br/ojs/index.php/EspacoAcademico/article/view/36386. Acesso em: set. 2020. 
BRASIL. Constituição da República Federativa do Brasil: texto constitucional promulgado em 5 de outubro de 1988, consolidado até a Emenda Constitucional n 99/17. Brasília: Senado Federal. Coordenação de Edições Técnicas, 2017.

BRASIL. Lei de diretrizes e bases da educação nacional - LDBEN. - Brasília: Senado Federal, Coordenação de Edições Técnicas, 2017.

CÂMARA DOS DEPUTADOS. Projeto de Lei 867/2015. Inclui, entre as diretrizes e bases da educação nacional, o “Programa Escola sem Partido" - Apensado ao PL 7180/2014. Brasília: 23 mar. 2015. Disponível em: http://www.camara.gov.br/proposicoesWeb/prop_mostrarintegra?codteor $=1230836 \&$ file name $=P L+7180 / 2014$. Acesso em: out. 2020.

CÂMARA DOS DEPUTADOS. Projeto de Lei 246/2019. Institui o "Programa Escola sem Partido". Disponível em:

https://www.camara.leg.br/proposicoesWeb/fichadetramitacao?idProposicao=2190752. Acesso em: out. 2020.

CARVALHO, Celso. O discurso de despolitização como meio de politização da educação: a ação ideológica do movimento Escola sem Partido. In: BATISTA, Eraldo Leme; ORSO, Paulino José; LUCENA, Carlos (Org.). Escola sem partido ou a escola da mordaça e do partido único a serviço do capital. Uberlândia: Navegando Publicações, p. 49-68, 2019.

EL PAís. Movimento Escola Sem Partido: o professor da minha filha comparou Che Guevara a São Francisco de Assis. EL PAís, S.P., 26 jun. 2016. Caderno Brasil, 2016.

ESPINOSA, Betty R. Solano; QUEIROZ, Felipe B. Campanuci. Breve análise sobre as redes da Escola sem Partido. In: FRIGOTTO, Gaudêncio (Org.). Escola "sem" Partido: esfinge que ameaça a educação e a sociedade Brasileira. Rio de Janeiro: LPP/UERJ, p. 49-62, 2017.

ESP. ESCOLA SEM PARTIDO. Disponível em: http://www.escolasempartido.org. Acesso em: ago. 2019.

FERRAZ, Roselane Duarte. A BNCC e os desafios aos profissionais da docência: debates necessários. Revista Brasileira de Educação de Jovens e Adultos. Salvador, v.7. p. 99-111. Disponível em: https://www.revistas.uneb.br/index.php/educajovenseadultos/article/view/9830. Acesso: 25 de nov. 2020.

FERREIRA, Lúcia Gracia; FERRAZ, Roselane Duarte. O contexto da educação, das políticas educacionais e do currículo: percepções a partir da Base Nacional Comum Curricular.

Revista FORPROLL. V. 4, n. 1, 2020. p. 5-30. Disponível:

https://drive.google.com/file/d/1X2TqZokY_bFr3SAz4uHv3PfNzmUQF6zX/view. Acesso: 20 jul. 2020.

FERREIRA, Lucia Gracia; ABREU, Roberta Melo de Andrade. Características e desafios dos/nos anos iniciais do ensinofundamental: vozes de estagiários. Revista de Estudos em Educação e Diversidade. v. 2, n.5, 2021. p. 1-31. 2021. Disponível:

https://periodicos2.uesb.br/index.php/reed/article/view/9557?fbclid=IwAR2zmosMESp6XjlSZmrXIXKydP4bxz79hhPaSXIBorTGQOz308F3ED55IE. Acesso: 19 out. 2021.

FERREIRA, Lúcia Gracia; FERRAZ, Roselane Duarte; FERRAZ, Rita de Cássia Souza Nascimento. Diretrizes Curriculares Nacionais para formação de professores: desafios e configurações para as licenciaturas. PrepintSCIELO. Disponível em: 
-Revista de Iniciação à Docência, v.6, n.2, 2021-

Publicação: dezembro, 2021 - ISSN 2525-4332

https://preprints.scielo.org/index.php/scielo/preprint/view/2228/3704. Acesso em: 19 out. 2021.

FREIRE, Paulo. Pedagogia do oprimido. 69. ed. Rio de Janeiro/São Paulo: Paz e Terra, 2019 .

FREIRE, Paulo. Pedagogia da Autonomia: saberes necessários à prática educativa. São Paulo: Paz e Terra, 1996.

FRIGOTTO, Gaudêncio (Org.). Escola "sem" Partido: esfinge que ameaça a educação e a sociedade Brasileira. Rio de Janeiro: LPP/UERJ, p. 17-34, 2017.

FRIGOTTO, Gaudêncio. Prefácio. In: BATISTA, Eraldo Leme; ORSO, Paulino José; LUCENA, Carlos. (Orgs.). Escola sem partido ou escola da mordaça e do partido único a serviço do capital. Uberlândia: Navegando Publicações, p. 1-9, 2019.

GIL, Antônio Carlos. Métodos e técnicas de pesquisa social. 6. ed. São Paulo: Atlas, 2008.

GIROUX, Henry A. Os professores como intelectuais: rumo a uma pedagogia crítica da aprendizagem. Tradução Daniel Bueno. Porto Alegre: Artes Médicas, p. 157-164, 1997.

GONDIM, Larissa C. D. O conceito de neutralidade: aspectos políticos e jurídicos. In:

Filosofia do Direito I. Florianópolis: CONPEDI, vol. 1, p. 191-207, 2014.

LAKATOS, Eva Maria; MARCONI, Marina de Andrade. Fundamentos de metodologia científica. 5. ed. São Paulo: Atlas, 2003.

MANHAS, Cleomar. Nada mais ideológico que “Escola sem Partido”. In: Ação Educativa Assessoria, Pesquisa e Informação (Org.). A ideologia do movimento Escola Sem Partido: 20 autores desmontam o discurso. São Paulo: Ação Educativa, p. 15-21, 2016.

MARINHO, João; IERVOLINO, Thais; NICOLAV, Vanessa. Sem partido e sem educação? Conheça os projetos de lei que questionam a formação cidadã na sala de aula. Educação \& Participação. 30 jun. 2016. Disponível em:

https://educacaoeparticipacao.org.br/acontece/sem-partido-e-semeducacao/. Acesso em: out. 2020.

MIGUEL, Luís Felipe. Da “doutrinação marxista” à “ideologia de gênero" - Escola sem partido e as leis da mordaça no parlamento brasileiro. In: Revista Direito e Práxis, v. 7, n. 15, p.590-621, 2016. Disponível em: https://www.redalyc.org/pdf/3509/350947688019.pdf. Acesso em: set. 2020.

MOURA, Fernanda Pereira de. “ESCOLA SEM PARTIDO”: Relações entre Estado, Educação e Religião e os impactos no Ensino de História. Orientadora: Alessandra Carvalho. Dissertação de Mestrado submetida ao Programa de Pós-Graduação em Ensino de História, Instituto de História, da Universidade Federal do Rio de Janeiro - UFRJ, 2016.

OLIVEIRA, Edna Araujo S.; CERNY, Roseli Zen; AVILA, Silviane de Luca. A docência perante o projeto de lei “Escola sem Partido”. In: Revista Educação e Emancipação, v. 11, n. 3, p. 250-266, 2018. Disponível em: http://www.periodicoseletronicos.ufma.br/index.php/reducacaoemancipacao/article/view/97 35. Acesso em: ago. 2020.

PENNA, Fernando de Araújo. O Escola sem Partido como chave de leitura do fenômeno educacional. In: FRIGOTTO, Gaudêncio (Org.). Escola "sem" Partido: esfinge que ameaça a educação e a sociedade Brasileira. Rio de Janeiro: LPP/UERJ, p. 35-48, 2017. 
PENNA, Fernando de Araújo. O ódio aos professores. In: Ação Educativa Assessoria, Pesquisa e Informação (Org.). A ideologia do movimento Escola Sem Partido: 20 autores desmontam o discurso. São Paulo: Ação Educativa, p. 93-100, 2016.

RAMOS, Moacyr Salles; SANTORO, Ana Cecília dos Santos. Pensamento freireano em tempos de escola sem partido. In: Inter-Ação, v. 42, n. 1, p. 140-158, 2017. Disponível em: https://www.revistas.ufg.br/interacao/article/view/44076. Acesso em: set. 2020.

RIO DE JANEIRO. Alerj. Projeto de Lei $\mathbf{n}^{\circ} \mathbf{2 . 9 7 4 / 2 0 1 4}$. Cria, no âmbito do sistema de ensino do Estado do Rio de Janeiro, o “Programa Escola Sem Partido”. 15 mai. 2014a. Disponível em: http://alerjln1.alerj.rj.gov.br/scpro1115.nsf/oc5bf5cde95601f903256caa0023131b/45741a7ezccdc50a83257c980062a2c2?OpenDocument\&Highlight=0,2974\%2F2014. Acesso em: out. 2020.

RIO DE JANEIRO. Câmara Municipal. Projeto de Lei 867/2014. Cria, no âmbito do sistema de ensino do município, o "Programa Escola Sem Partido". 03 jun. 2014b. Disponível em: http://mail.camara.rj.gov.br/APL/Legislativos/scpro1316.nsf/f6d54agbfogac233032579deoo6bfef6/ 5573ae961660b4cd83257ceboo6bc7d4?OpenDocument. Acesso em: out. 2020.

SANTOS, Jaciara de Oliveira Santanna; BARRETO, Andréia Cristina Freitas. A INVISIBILIDADE DO TRABALHO DOCENTE EM TEMPOS DE PANDEMIA: DAS POLÍTICAS ÀS PRÁTICAS. Revista Latino-Americana de Estudos Científicos, p. 232-241, 2021. Disponível em: https://periodicos.ufes.br/ipa/article/view/36693. Acesso em 20. out. 2021.

SILVEIRA, Zuleide S. Onda conservadora: o emergente movimento Escola sem Partido. In: BATISTA, Eraldo Leme; ORSO, Paulino José; LUCENA, Carlos (Org.). Escola sem partido ou a escola da mordaça e do partido único a serviço do capital. Uberlândia: Navegando Publicações, p. 17-47, 2019.

SOUZA, Ester Maria de Figueiredo Souza. FERREIRA, Lúcia Gracia. A prática como componente curricular: (re)indagações para a formação docente. Revista Práxis Educacional, Vitória da Conquista, Bahia, Brasil, v. 15, n. 34, p. 195-210, Edição Especial, 2019. Disponível em: http://periodicos2.uesb.br/index.php/praxis/article/view/5505/4183. Acesso em: 29 nov. 2019.

TAFFAREL, Celi Nelza Zulke; JÚNIOR, Cláudio de Lira Santos; CARVALHO, Marize Souza; BELTRÃO, José Arlen. Escola sem Partido: a necessidade do controle ideológico dos professores para se manter a exploração de classe e o imperialismo. In: BATISTA, Eraldo Leme; ORSO, Paulino José; LUCENA, Carlos (Org.). Escola sem partido ou a escola da mordaça e do partido único a serviço do capital. Uberlândia: Navegando Publicações, p. 163-194, 2019.

ZAN, Dirce; MAZZA, Débora. Escola sem Partido? É possível? Jornal da Unicamp, Campinas, 05 de dezembro de 2018. Disponível em:

https://www.unicamp.br/unicamp/ju/artigos/educacao/escola-sem-partido-e-possivel. Acesso em: jul. 2020. 